\title{
Certainty and our sense of acquaintance with experiences
}

\begin{abstract}
Why do we tend to think that phenomenal consciousness poses a hard problem? The answer seems to lie in part in the fact that we have the impression that phenomenal experiences are presented to us in a particularly immediate and revelatory way: we have a sense of acquaintance with our experiences. Recent views have offered resources to explain such persisting impression, by hypothesizing that the very design of our cognitive systems inevitably leads us to hold beliefs about our own experiences with certainty. I argue against this kind of "designed certainty" views. First, I claim that it is doubtful that we really hold beliefs about our own experiences with certainty - in any sense of certainty that would make our phenomenal beliefs special. Second, I claim that, even if it were the case that we hold beliefs about experiences with certainty, this would fall short of explaining our sense of acquaintance.
\end{abstract}

\section{Introduction ${ }^{1}$}

Many philosophers think that phenomenal consciousness poses a hard problem (Chalmers, 1995): it seems extremely difficult to explain why the functioning of the brain gives rise to phenomenal experiences. It has been recently suggested that, in order to approach this hard problem, we should solve first the meta-problem of consciousness (Chalmers, 2018): that is, we should explain how and why we think that there is a hard problem of consciousness. One fact seems particularly operative in our thinking that phenomenal consciousness poses a hard problem: the fact that we have a sense of acquaintance with our phenomenal experiences. We have the impression that experiences are presented to us in some sort of peculiarly direct, concrete, immediate and revelatory way. Solving the meta-problem thus seems to require explaining our sense of acquaintance with experiences.

A recent promising line of thought has lately been gaining traction (Clark et al., 2019; Schwarz, 2018, 2019). According to this line of thought, our sense that experiences are presented in a peculiarly immediate and revelatory way, itself crucial for our impression that consciousness is

\footnotetext{
${ }^{1}$ I would like to thank the audience at the ANU as well as Wolfgang Schwarz for their comments.
} 
mysterious and puzzling, can be explained by the fact that our cognitive systems are designed to hold propositions about their own experiences with certainty - as it is advantageous for them to do so. I argue against such "designed certainty views", by showing that they cannot account for our sense of acquaintance with experiences. Indeed, while I take it that we do have a sense of acquaintance with our experiences, it is very doubtful that we hold beliefs about them with certainty (at least not in a distinctive sense of certainty, that would make phenomenal beliefs special). Moreover, even if we did, this would fall short of explaining our sense of acquaintance with experiences. Indeed, our sense of acquaintance is not constituted (nor systematically caused) by such certainty of phenomenal beliefs.

After some definitions ( $(2)$, I present various attempts at explaining our sense of acquaintance, and I focus on designed certainty views $(\S 3)$. I raise a first problem for designed certainty views: I argue that we do not really hold beliefs about our own experiences with certainty - at least not in a sense of "certainty" that would make phenomenal beliefs special ( $\$ 4)$. I then raise a second problem for designed certainty views: I argue that, even if we were distinctively certain of our experiences, this would fall short of explaining our sense of acquaintance ( $\$ 5)$. I then close with some concluding remarks (§6).

\section{Phenomenal consciousness and our sense of acquaintance with experiences}

Phenomenal experiences (or "phenomenal states", "conscious experiences") are putative mental states endowed with phenomenal properties (or "qualia"). In virtue of these phenomenal properties, there is "something it is like" to be in these states. Smelling a rose, seeing a red cherry, feeling pain in one's tooth when one undergoes dentistry: these states are typical examples of phenomenal experiences. A subject who enters such states is phenomenally conscious and possesses phenomenal consciousness. It is usually admitted that phenomenal consciousness can be distinguished, at least conceptually, from access consciousness - accessconscious states being defined as mental states, the content of which is available for use in reasoning and rational control of speech and action (Block, 1995). 
Phenomenal consciousness is often said to create a "hard problem" (Chalmers, 1995) for the science of the mind. Why do brain processes (a set of chemical and electrical processes) give rise to phenomenal experiences, endowed with genuine phenomenal properties? This problem seems particularly puzzling. It differs from the "easy problems" of consciousness - the problems of explaining how brain processes can fulfill all kinds of functions usually associated with consciousness (detecting and categorizing stimuli, integrating information, reporting internal states, etc.).

David Chalmers, who coined the label "hard problem", has recently argued that one way to shed light on this seemingly intractable hard problem might be to solve another, easy problem, which bears a close relationship to the hard problem: the meta-problem of consciousness. The meta-problem is, roughly, the problem of explaining why we think that phenomenal consciousness poses a hard problem. More precisely, solving the meta-problem means giving a physical and/or functional explanation of various problem intuitions (intuitions that phenomenal consciousness is puzzling and hard to explain). These intuitions must themselves be conceived in a purely physico-functional manner (say, as dispositions to produce certain judgments functionally conceived, or certain utterances), for the meta-problem to constitute a genuine easy problem.

Chalmers considers many intuitions to be part of the explanandum of the meta-problem: explanatory intuitions (intuitions that consciousness is hard to explain), metaphysical intuitions (intuitions that consciousness is not purely physico-functional), modal intuitions (intuitions that the phenomenal can be decorrelated from the physico-functional), knowledge intuitions (intuitions that the first-person perspective offers a special kind of knowledge of consciousness - for example, that Mary, the brilliant neuroscientist who lives in a black-and-white room, does not fully know what an experience of red is before she has one), etc. One of them, in the vicinity of knowledge intuitions, deserves particular attention: what Chalmers calls our sense of acquaintance with experiences. We have the impression that we are acquainted with our phenomenal experiences in some sort of distinctive way (we do not have the same sense of acquaintance with external physical events, or with dispositional mental states). What does this sense of acquaintance exactly consist in? Chalmers thinks that it has two components (Chalmers, 2018, p. 25): first, a sense of presentation, as we have the impression that, when we 
introspect, our phenomenal experiences are presented to us in some sort of direct, concrete and immediate way (for this distinction, see also Goff, 2017). Second, a sense of revelation - we have the impression that introspective presentations of phenomenal experiences give us the full nature of phenomenal properties. ${ }^{2}$

Chalmers notes that this intuition of acquaintance is crucial to our impression that consciousness poses a hard problem: "one could argue that it is the sense of acquaintance specifically [that] plays the central role in generating our puzzlement about consciousness" (Chalmers, 2018, p. 25). He also remarks that the intuition of revelation (a component of the intuition of acquaintance) has been identified both by prominent materialists (Lewis, 1995) and anti-materialists (Goff, 2017) as the crucial intuition that must be rejected (or embraced) in order to make their case. I agree with this diagnosis. Without a strong intuition of revelation, I do not think that many of us would experience such intuitive resistance to the (standard) physicalist view that phenomenal consciousness is nothing over and above certain physicalfunctional processes (Dretske, 1995; Smart, 1959). Such a statement is arguably at odds with what introspection presents of consciousness, but this creates an issue only because we tend to think that consciousness really has the nature that introspection presents. If we did not have a strong intuition of presentation, on the other hand, I do not think that we would intuitively resist "strong illusionist" materialists so much when they state that phenomenal consciousness just does not exist, although it seems to exist (Frankish, 2016). This thesis seems preposterous and obviously false to many of us, mainly because we have a strong sense that phenomenal experiences are immediately and concretely presented to us when we have them (they are "present in person", so to speak), in a way that leaves no room for doubt.

There are debates regarding the distribution and the robustness of problem intuitions. Are all of these intuitions universally shared, or at least widely shared (Irvine, 2019; Sytsma \& Machery, 2010; Sytsma \& Ozdemir, 2019)? How robust are they? - how dependent on cultural (Balmer, 2020), sociological (Lau \& Michel, 2019) and/or linguistic (Wierzbicka, 2010, 2019) factors are they? I will set these debates aside here. I follow Chalmers in assuming claims (A-C): (A)

\footnotetext{
${ }^{2}$ In Chalmers' paper, it is not clear whether this "sense of acquaintance" is a genuine problem intuition (a certain disposition to believe something about consciousness), or something more general, that gives rise to a series of problem intuitions. I will set aside this worry here: I will talk indifferently of the "sense" of acquaintance and of the "intuition" of acquaintance.
} 
Problem intuitions are widely (if not universally) shared among adult humans. (B) They have a high degree of robustness and are largely cognitively impenetrable. (C) The intuition of acquaintance (with its two components: presentation and revelation) features among problem intuitions ${ }^{3}$, and it is particularly crucial in generating and maintaining our impression that consciousness poses a hard problem.

\section{Explaining our sense of acquaintance}

\section{A. Some attempts at explaining our sense of acquaintance}

There have been numerous attempts at giving a physico-functional explanation of our sense of acquaintance with experiences. I intend to examine and criticize one particular line of thought, first presented by Wolfgang Schwarz (Schwarz, 2018, 2019) and endorsed, with some modifications, by Andy Clark, Karl Friston and Sam Wilkinson (Clark et al., 2019). However, before I turn to this line of thought, a few words about other physicalist takes on our sense of acquaintance.

First, there have been recent attempts at giving physicalist conceptions of acquaintance itself. Some philosophers have tried to understand how acquaintance (Balog, 2012; Coleman, 2018), or something in the vicinity (Kriegel, 2009), can be naturalized and physically realized. I will not focus on their attempts here. Indeed, the project of explaining acquaintance (especially considered in some sort of watered-down physicalist version) is different from the project of explaining our sense of acquaintance. One can claim that some physical states of our brain, say,

\footnotetext{
${ }^{3}$ An influential line of thinking, initiated by Harman and Tye (Harman, 1990; Tye, 2002), claims that experiences are transparent: the only qualities we introspectively find in experiences are qualities of objects, not of experiences themselves. Proponents of transparency might be interpreted as stating that we do not have a sense of acquaintance with experiential qualities. This suggests that the intuition of acquaintance is not widely shared after all - as it would not be shared by the numerous philosophers who are attracted to the transparency thesis! However, the transparency view is also naturally seen as suggesting that we feel so acquainted with objectual qualities, and maybe even with experiences themselves - not as bearers of sui generis qualities, but as acts of acquaintance with objectual qualities (this is Chalmers' view). Hence, it is not clear that proponents of transparency can easily deny that we have a problematic intuition of acquaintance of some sort, even if they might deny that we feel acquainted with experiential qualities irreducible to presentations of objectual qualities. I think that similar things could be said about views such as Alex Byrne's (Byrne, 2009), according to which experience-talk is misleading, and so that there are properly speaking no "experiences". The detailed discussion of such views falls beyond the scope of this paper.
} 
satisfy many of the properties of what we call acquaintance, without having explained that we have a sense of acquaintance. Conversely, one can explain fully our sense of acquaintance in a physico-functional framework even if one lacks a physicalist conception of acquaintance itself - for example, if one sees acquaintance as merely illusory. Therefore, a physico-functional theory of acquaintance and a physico-functional theory of our sense of acquaintance are two different things. One can look for the first without bothering about the second, and conversely. ${ }^{4}$

Second, some have tried to explain our sense of acquaintance with experiences as the result of some sort of mistake that we tend to make, because of the shortcomings of our introspective processes. They stressed the fact that introspection provides us only with partial information: it tells us in which mental states we are, but is silent on the nature of these states, as well as the details of the introspective process. It is then hypothesized that this partial access makes us infer mistakenly that introspection gives us some kind of direct, accurate and complete access to our mental states. This constitutes our sense of presentation and revelation with conscious states. Daniel Dennett has defended a view of this kind (Dennett, 2017, chap. 14). Another source for this sort of idea can be found in the work of David Armstrong and his "headless woman illusion" defense of materialism (Armstrong, 1968; for a recent defense and a link to our sense of revelation, see (Williford, 2020)). ${ }^{5}$

Derk Pereboom (Pereboom, 2009, 2011), also sees our sense of acquaintance as the result of a mistake that we tend to make because of the shortcomings of introspection. In Pereboom's view, introspection differs from perception, because we have no way to check the accuracy of introspective judgments independently of introspection itself (while we can use various instruments to check the accuracy of our perceptions). Because of this, we struggle to represent possible introspective mistakes. This leads us to infer mistakenly that there simply cannot be such introspective mistakes, so that introspection must be direct and revelatory.

\footnotetext{
${ }^{4}$ For the view that acquaintance itself can be naturalized, although our sense of acquaintance can perhaps not be fully explained in physical-functional terms, see (Balog, 2020).

${ }^{5}$ This kind of approach is similar to the approach labeled "Introspective Opacity" by David Chalmers in his metaproblem paper (Chalmers, 2018, p. 22-23).
} 
These lines of thought all suffer, according to me, from the same flaw. They see our sense of acquaintance as the result of some sort of incorrect inference (that we tend to make because of the shortcomings of introspection). However, for this reason, they are not in a good position to explain the robustness and the persistence of our sense of acquaintance. If our sense of acquaintance were the product of some kind of reasoning error or mistaken inference, we should be able to get rid of it provided we made the right kind of cognitive effort: the process generating our sense of acquaintance should be cognitively penetrable. However, it does not seem to be the case. I will not argue at length for this here, as I have developed these arguments elsewhere. ${ }^{6}$ I will assume that a satisfying explanation of our sense of acquaintance has to conceive of this sense of acquaintance as an inescapable feature of our cognitive system, and not simply as the result of a mistake we tend to make.

\section{B. Designed certainty views}

One promising line of thought has been put forth recently, first by Wolfgang Schwarz, and then, with some modifications, by Andy Clark, Karl Friston and Sam Wilkinson. It provides resources to explain our sense that we know our own experiences in some sort of unique and peculiar way (our sense of acquaintance) as a direct consequence of some robust feature of our cognitive systems. Because this line of thought, as I interpret it, consists in claiming that the very design of our cognitive systems leads us to hold beliefs about experiences with certainty, I call these views "designed certainty views". 7

Wolfgang Schwarz (Schwarz, 2018, 2019) originally develops his conception within a Bayesian picture - although the point I want to discuss can be abstracted from this framework. He suggests that, if we conceive of our cognitive systems as kinds of Bayesian perceivers, which need to update their beliefs upon incoming sensory stimuli, it could be advantageous for our

\footnotetext{
${ }^{6} \mathrm{I}$ have argued at length against Pereboom's explanation of our sense that introspection is in some sense infallible in (Kammerer, 2018). See (Pereboom, 2019) for Pereboom's response. Regarding Dennett's view or views inspired by Armstrong, I argued in (Kammerer, 2019a) that it predicts that the processes generating our problem intuitions should be cognitively penetrable, while they are not. David Chalmers also criticizes views of this kind (Chalmers, 2018, p. 22-23), for comparable reasons.

7 "Certainty" is ambiguous between a psychological and an epistemic meaning (on which I will say more later). I use here the psychological sense: beliefs or judgments are (psychologically) certain when they are held with a maximal degree of confidence.
} 
cognitive systems to entertain some absolute certainty towards certain "imaginary" propositions in order to facilitate this process of belief updating. The holding of such imaginary propositions would track sensory input. The propositions would be held with absolute certainty by the system, while the propositions corresponding to the distal fact usually corresponding to the sensory input (for example, in the case of a sensory perception of red, the presence of something red) would never be judged fully certain (although in standard cases they would be inferred with high probability from the imaginary propositions). These imaginary propositions are phenomenal propositions, although Schwarz think that they are much more fine-grained that the standard examples of phenomenal propositions that we are able to express in natural language (“I experience red", I feel pain"). The key idea is that we should expect our cognitive systems to be $100 \%$ certain of such phenomenal ("imaginary") propositions, but not of other propositions.

Andy Clark, Karl Friston and Sam Wilkinson (Clark et al., 2019) accept Schwarz's conception, with some modifications. The most important modifications for our discussion are the following8: (A) They think that our cognitive systems hold beliefs about phenomenal propositions with high certainty, but not full certainty (and, therefore, not 100\% certainty), although this high certainty is reported as full certainty at the agentive level (Clark et al., 2019, p. 24-25). (B) They claim that holding phenomenal propositions with high certainty is compatible with the cognitive system taking a skeptical stance about these phenomenal propositions at a meta-level (Clark et al., 2019, p. 25) - more on that later.

Both Schwarz's view and Clark et al.'s view aim at solving the meta-problem of consciousness. They see this designed certainty feature as central in explaining why we have the intuition that consciousness is puzzling, hard to explain, and distinct from the physical (Clark et al., 2019, p. 30; Schwarz, 2019, p. 224-225). The designed certainty feature is not supposed to be the whole story provided by such accounts when it comes to explaining why consciousness seems puzzling. For example, in Schwarz's account, the fact that this certainty bears on a kind of fact which, from the point of view of the system, is "only contingently associated with ordinary

\footnotetext{
${ }^{8}$ Clark, Friston and Wilkinson also develop a rich conception of phenomenality as corresponding to certain midlevel encodings within the human cognitive system, considered as a hierarchical Bayesian engine. I will not talk about these aspects here, even if they are supposed to explain some aspects of our sense of acquaintance (the apparent "concreteness" of experience).
} 
hypotheses about the world" also plays an essential role (Schwarz, 2019, p. 222). In Clark et al.'s account, the fact that representations of qualia correspond to mid-level encodings is also important. However, I think that it is fair to say that this certainty feature is supposed to be the key feature posited by these accounts to explain why we have an intuition of acquaintance. ${ }^{9}$ Other features might explain other problems intuitions, but when it comes to the intuition of acquaintance, certainty does the heavy lifting. ${ }^{10}$

Designed certainty views have a crucial advantage over the other previously mentioned physicalist explanations of our sense of acquaintance: in one word, they see our sense of acquaintance with experiences as a feature, not a bug. In such views, our tendency to hold phenomenal beliefs with certainty is an inescapable property of our cognitive systems, which stems from the very design of these systems. Designed certainty views thus escape the objection addressed above to other explanations of our sense of acquaintance: they predict that our certainty regarding phenomenal experiences will persist in spite of all our efforts - which indeed, seems to be what happens. They predict that it will not disappear on reflection, nor after the acquisition of new information, as it is not the result of some sort of mistaken inference (reasoning error, fallacy, etc.), but an inescapable and cognitively impenetrable feature, inherent to the design of our cognitive system. ${ }^{11}$

This makes designed certainty views prima facie very attractive. David Chalmers, for instance, recently claimed that these views - together with my own view developed in (Kammerer, 2019c) - are "[a]mong the most promising strategies" to solve the meta-problem of consciousness (Chalmers, 2020, p. 203). However, I do not think that designed certainty views

\footnotetext{
${ }^{9}$ Although these accounts are not formulated using the vocabulary of "acquaintance", I think that it is legitimate to interpret them as aiming notably at an explanation of our sense of acquaintance. Indeed, they aim at explaining why we have the strong and inescapable impression that we know our own experiences in some uniquely reliable way, which makes the puzzling character of consciousness particularly persistent, and renders both standard realist materialism and illusionism hard to accept. Moreover, note that, even if it turned out that the intuition of acquaintance is not the main explanatory target of these views (not more, say, than other problems intuitions), it would still be extremely relevant, for someone who thinks that the intuition of acquaintance is crucial to the metaproblem, to examine how such views fare when it comes to explaining this intuition.

${ }^{10}$ I do not think that any other feature posited by these views could be interpreted as explanatory of our sense of acquaintance. However, if it turns out that these views admit other potential explanans, one can read the following arguments as a criticism, not of these views per se, but of a rational reconstruction of these views in which certainty towards phenomenal propositions is the explanans of our intuition of acquaintance.

${ }^{11}$ One other advantage (which I will pass over quickly) of designed certainty views is that they see this designed certainty feature as an advantageous feature of our cognitive architecture, which makes then these features easier to explain evolutionarily.
} 
are correct. I will now raise two problems for such views. First, I will argue against designed certainty views, by showing that it is very doubtful that we are really certain of our own experiences, and that if we are, it is only in a sense of "certainty" that does not make this experiential certainty distinctive. Second, I will argue that, even if we were certain of our own experiences, this would not explain our sense of acquaintance.

\section{Are we really certain of our experiences?}

\section{A. Are we really $100 \%$ certain of our own experiences?}

Let us start with the first problem for designed certainty views. I claim that it is not plausible that we really are certain of our own experiences, if we understand "certainty" as meaning $100 \%$ confidence. Here are three possible counterexamples.

a) In some (rare) cases, we seem ready to admit that we can commit introspective errors about some supposedly obvious properties of our experiences. Pereboom's "fraternity" case (Pereboom, 2011, p. 22-23) ${ }^{12}$ thus features a college student initiated into a fraternity. The student is shown a sharp razor and is then blindfolded. He is told that the razor is about to cut his throat. When he suddenly feels something on his throat, he judges that it is pain - and screams. One second later he realizes that he is only having a sensation of cold (an icicle was put on his throat instead of a razor). It is reasonable to think that, in this case, the student would be ready to admit that his first introspective judgment was mistaken. If that is the case, this means that we can sometimes revise our introspective judgments. This goes against the idea that we hold our judgments about our own phenomenal experiences with $100 \%$ certainty.

b) Cases where we admit that we make introspective errors are even more common when we focus on less obvious properties of our experiences. One classical example concerns the detailed character of the visual field. It seems that some people spontaneously judge that their own visual

\footnotetext{
${ }^{12}$ Pereboom borrows this example from from Christopher Hill (Hill, 1991, p. 128-129), who himself borrowed it from Rogers Albritton.
} 
experiences are rich and detailed (e.g. colored) throughout their visual field. Nevertheless, it is rather easy to become convinced that our visual field is not thus detailed (e.g. we see no color in the peripheral visual field), so that we are the victims of some kind of illusion (Blackmore, 2002). We should not be able to do that if we were $100 \%$ certain of our judgments regarding our own phenomenal experiences.

c) The most radical counterexample to the view that we are $100 \%$ certain of our own experiences is the fact that there are people who believe that no one (including themselves) has phenomenal experiences, even though they recognize that it (non-phenomenally) seems to us that we do: philosophers who endorse "strong illusionism" (Frankish, 2016). If humans were really forming judgments about their own experiences with $100 \%$ confidence, there should be no strong illusionists on this planet.

Of course, someone who holds that we really are $100 \%$ certain of our own experiences might find answers to these counterexamples. Against the visual field illusion counterexample, they might restrict their claim to only some phenomenal judgments (judgments bearing on obvious and central properties of our experiences). Against the fraternity case illusion counterexample, they might distinguish between existence judgments and classificatory judgments, and hold that only the first are held with $100 \%$ certainty (they might also want to include some very coarsegrained classificatory judgments). Against the strong illusionism objection, they could suggest, either that strong illusionists do not really believe what they claim to believe (because they are insincere, or because they are mistaken about what they really believe), or more plausibly, that illusionists' belief in strong illusionism is located at some sort of meta-level, which does not contradict their low-level $100 \%$ certainty about their own experiences. ${ }^{13}$ However, endorsing all of these answers leads to a view which seriously departs from designed certainty views as I described them above: a view in which the only judgments held with $100 \%$ certainty are nonclassificatory phenomenal judgments (or very coarse-grained classificatory judgments) about a restricted class of experiences - and this $100 \%$ certainty does not transmit to the personal level.

\footnotetext{
${ }^{13}$ This might follow from what Schwarz suggests when he writes : “A system's world model need not match its considered judgments about metaphysical reality" (Schwarz, 2019, p. 225).
} 
All of this puts some serious pressure on designed certainty views, if we understand "certainty" as meaning " $100 \%$ certainty". Can we find more hope in a more relaxed understanding of "certainty"?

\section{B. Is near-certainty distinctive?}

Maybe one can escape these difficulties by claiming, as Clark et al. do, that our cognitive systems hold beliefs about phenomenal experiences with high certainty or near-certainty, but not full certainty - say, with $99.99 \%$ confidence, but not $100 \%$ confidence. This would certainly help us answer the previous objections: if we "merely" have $99.99 \%$ confidence in phenomenal judgments, it is not that surprising that, in certain (rare) situations, some of us might come to doubt or reject some of their phenomenal judgments (see the counterexamples above). ${ }^{14}$

However, this view also faces a - different - problem: it seems that we judge many nonphenomenal propositions with near-certainty - with a very high degree of confidence. Think about the propositions that consist in (or imply) the negation of a skeptical scenario: "I have two hands"; "I am not a brain in a vat"; "The world has existed for more than 10 seconds"; "Other humans have minds comparable to mine", etc. Think also about many very mundane propositions: "My name is François", "I am not the Queen of the United Kingdom”, etc. It is very likely that all these propositions are believed with near-certainty - with a degree of confidence neighboring $99.99 \%$. So, near-certainty is in no way distinctive of our beliefs about experiences. ${ }^{15}$

Moreover, it is quite clear that none of these other facts about which we are nearly certain create issues similar to the problem of phenomenal experiences. These facts do not seem to us to be directly presented and revealed; we can easily envision possible scenarios in which these facts

\footnotetext{
${ }^{14}$ Note however that it is not for this kind of reason that Clark et al. reject Schwarz's view that we hold phenomenal judgments with $100 \%$ certainty. Their own motivation is linked to the way in which multi-level Bayesian updaters work : "For technical reasons it is usually not a good idea for the processing itself to reach $100 \%$ certainty as this locks solutions into place in a way that blocks ongoing multi-level processing" (Clark et al., 2019, p. 25).

15 This is not to say that full certainty is distinctive of our beliefs about experiences. For example, it is arguably believe that we have non-experiential full certainty (say, that $1+1=2$ ). I will discuss that example later.
} 
do not obtain. Therefore, near-certainty not only is not distinctive of our beliefs about experiences; it also fails to capture adequately our impression that experiences are presented in a peculiarly direct and revelatory way. This weighs against designed certainty views that would understand "certainty" as meaning simply "near-certainty".

C. Beyond near-certainty and full certainty: can we have it both ways?

Claiming that we have full certainty towards our own experiences is problematic, because we sometimes doubt or reject some of our introspective judgments about experiences. Claiming that we merely have near-certainty is unlikely to explain our impression that experiences are presented in a peculiar way, given that near-certainty is not at all distinctive of phenomenal judgments. Could we mix the two conceptions, and try to have it both ways? Maybe this is what Clark et al. try to do when they make sure to distinguish between our mere near-certainty towards experiences, which is computed by sub-personal processes, and the $100 \%$ certainty had at the "agentive" level, triggered as soon as the sub-personal processes reach a certain confidence threshold (Clark et al., 2019, p. 25).

However, locating our full certainty towards experience at the agentive, personal level (while the "probabilistic underpinnings in the whirl of processing" stick to near-certainty) creates some serious issues. First, it becomes hard to understand why agents are able to do what Clark and collaborators precisely claim they do: "reflect somewhat skeptically about their own sensory certainty" (Clark et al., 2019, p. 25). Indeed, if the agentive level were to be the only locus of full certainty, skeptical worries precisely should never arise at the level of the agent. Strong illusionists, for example, could only be such at a sub-personal level - which seems plainly false. If anything, the opposite is true: it seems that it is at the personal level that we sometimes come to doubt or reject some of our introspective judgments (this is quite obvious in the strong illusionism counterexample). So, limiting our full certainty towards experiences at the personal level does not help with these counterexamples.

Another way to make sense of what Clark and collaborators say requires us to interpret the idea that we have $100 \%$ agentive certainty regarding experiences as meaning, not that we have $100 \%$ 
agentive certainty towards the fact that we have certain experiences, but that we have $100 \%$ agentive certainty towards the fact that our first-level judgments regarding experiences are themselves held with $100 \%$ certainty. This interpretation of Clark et al.'s view departs from my previous understanding of designed certainty views (as well as from Schwarz's view), as in this interpretation a crucial role is played by the meta-level of second-order judgments regarding first-order judgments about experiences. In such "meta-certainty" view, the story goes like this: we undergo a number of processes leading to first-level judgments that we have some experiences, and these judgments are held with near-certainty (say, with $99.99 \%$ confidence). Then, at the meta-level, we form the meta-judgment, held with full certainty, that our first-level judgments that we have some experiences are held with full certainty.

I am not certain this is the correct way to interpret the view of Clark et al., as they go very quickly on this crucial point (note that all of this is entirely left out in Clark, 2019). However, even this sophisticated picture faces obvious objections. If this story were correct, we should expect subjects to entertain Moore's paradoxical statements of the form "P but I believe that not P" about their experiences - but they do not. For example, while introspectively representing that they are having an experience of red, they should be able to judge at the same time (A): "It could be the case that I am not really having an experience of red right now" (given that their first-level judgment about their experience of red is only held with $99.99 \%$ confidence) and (B): "I believe that it could not be the case that I am not really having an experience of red right now" (given that they judge that their judgment that they have an experience of red is $100 \%$ certain). However, we do not make such paradoxical claims.

It might be that there are other ways to articulate full certainty and near-certainty allowing us to have it both ways. However, such an account does not seem to me to be currently available.

To conclude this section: there is no sense of certainty, such that (i) we are really certain of our own experiences; (ii) this certainty is distinctive of our beliefs and judgments about our own experiences (which is required to capture our sense that experiences are presented to us in a unique way). This gives us a first reason to reject designed certainty views. 


\section{Why acquaintance really goes beyond certainty}

Let us suppose, for the sake of the argument, that we ignore this first problem: let us admit that we really form judgments about our own present experiences with $100 \%$ certainty (suppose we have found a way to answer the earlier counterexamples. Here I focus on full certainty, rather than on near-certainty or meta-certainty). We would still fall short of explaining our sense of acquaintance with experiences.

Indeed, I believe that our sense of acquaintance with experiences does not require certainty towards experiences, but that, even if it did (which is something I am happy to grant here for the sake of the argument), it would be much more than that. I will now argue for this. I will first show that there is an ontological distinction between certainty towards experiences and our sense of acquaintance: certainty cannot constitute our sense of acquaintance. Second, I will show that there is a psychological distinction between the two features: certainty would not systematically cause a sense of acquaintance. I will focus my attention on certainty, interpreted as meaning "full certainty", but I will also say a few words about near-certainty and metacertainty in the footnotes.

\section{A. The ontological distinction between certainty and our sense of acquaintance}

What kind of feature is certainty towards our own experiences? It is a feature of our judgments or beliefs regarding some of our own mental states. These judgments (or beliefs) are to be held with a certain degree of confidence, equal to $100 \%$ (a bit less for near-certainty). What kind of feature, on the other hand, is our sense of acquaintance with experiences? This sense of acquaintance, as I noted earlier, is the sense that our own experiences are known in a peculiar and unique way, in a way which explains that we experience a persistent intuitive resistance both to "standard" materialism, as well as strong illusionism. A common way to elaborate this sense of acquaintance is to see it, for example, as comprising a sense of presentation (a sense that our phenomenal experiences are presented to us in some sort of direct, concrete and immediate way), and a sense of revelation (a sense that these presentations of phenomenal experiences reveal their full nature). However, whatever one's stance towards these particular 
definitions, what is clear is that this sense of acquaintance consists of intuitions about how phenomenal experiences are known.

Therefore, there is a crucial ontological distinction to make between certainty towards experience, a feature of our judgments regarding experiences and our sense of acquaintance, an intuition regarding our epistemic relation to experiences. The first feature is a feature of introspective judgments, the second feature is a disposition to form certain meta-introspective judgments, regarding the kind of introspective access we have to phenomenal experiences (an access arguably grounding introspective judgments). So, certainty towards experience and our sense of acquaintance are simply two different kinds of things: they are features located at a very different cognitive level (introspective level vs meta-introspective level). This gives us a strong reason to doubt that the first constitute the second: the two features are ontologically distinct.

Two remarks now: first, if certainty and our sense of acquaintance are so clearly ontologically distinct, one can wonder why it might have seemed to some philosophers that explaining the first could provide an explanation of the second. Setting aside the possibility of a systematic causal link between the two (more on that later), here is a possible explanation. The term "certainty" is polysemic (Reed, 2011). On the one hand, it refers to a psychological property: the property of a judgment or a belief which is held with a maximal degree of confidence. This form of certainty is sometimes called "psychological certainty": it is the form of certainty referred to in designed certainty views discussed here. However, "certainty" can also mean something else: epistemic certainty. Beliefs or judgments are epistemically certain when they have the highest possible epistemic status (a status which has historically been cashed out in terms of indubitability, or infallibility). The two properties are certainly related (plausibly, a belief is epistemically certain when one is justified in holding the belief with psychological certainty), which means certainty is not a case of mere homonymy - but they can also occur seperately. A judgment can be psychologically certain without being epistemically certain (think about a subject who is unjustifiably fully confident in one of their beliefs), or epistemically certain without being psychologically certain (think about a subject who fails to recognize that a given belief has the highest possible epistemic status). Crucially, one plausible way to interpret our sense of acquaintance (an intuition about our introspective access to 
experiences) is precisely to see it as the intuition that our introspective access to experiences is such that it makes our introspective beliefs about experiences epistemically certain. This might have led us to conclude (confusedly) that a view that explains our introspective beliefs about experiences as psychologically certain would explain our sense of acquaintance. However, I think that a careful distinction between epistemic and psychological certainty helps us when distinguishing ontologically between (psychological) certainty towards experiences and our sense of acquaintance - and shows that the first does not constitute the second.

Second: I distinguished between our certainty towards experience and our sense of acquaintance, by stressing that the first is a feature that arises at the introspective level, while the second arises at the meta-introspective level. One interpretation of the view of Clark et al. (the "meta-certainty view" - see section 3.C.), also seems to stress the importance of the metaintrospective level. Would such a version of designed certainty views be in a better position to explain our sense of acquaintance? To answer, one should first acknowledge that such "metacertainty views" depart importantly from the designed certainty approach originally put forth by Schwarz. It is also very unclear that this meta-certainty view really is the correct interpretation of what Clark et al.'s view. Nevertheless, it is true that the meta-certainty view seems to give a crucial role to the meta-introspective level - which is precisely where I think our sense of acquaintance is located.

However, the feature it focuses on must also be distinguished ontologically from our sense of acquaintance. Indeed, the meta-certainty view states that the crucial explanatory feature is the fact that we judge (with full certainty) that our introspective judgments are fully psychologically certain. It is then located at the meta-introspective level, but corresponds to judgments made about introspective judgments (and their degree of confidence), and not about the introspective access or justification which arguably grounds these judgments. On the other hand, our sense of acquaintance bears on our introspective access (and the quality of this access), not the confidence with which we hold our introspective judgments. Otherwise, our sense of acquaintance would not lead us to believe that consciousness must really be as it is introspectively presented to us (which is what makes us find consciousness puzzling), but simply, at most, to recognize that we have a strong tendency to think so. To understand why our sense of acquaintance plays the role it plays in generating our impression that consciousness 
is puzzling and hard to explain, we must recognize that it consists in an intuition about the quality (normatively conceived) of our introspective access, and not simply about the psychological strength of some of our own beliefs. In other words: our sense of acquaintance is the sense that our introspective access gives us epistemically certain beliefs, and it is distinct from the belief that introspection makes us form psychologically certain beliefs. This last feature is all that the meta-certainty view explains at best.

\section{B. The psychological distinction between certainty and our sense of acquaintance}

I argued that certainty and our sense of acquaintance are ontologically distinct: they are two different things. The first does not constitute the second. However, this is not enough to show that designed certainty views cannot explain our sense of acquaintance. Indeed, it might be that, although they are ontologically distinct, certainty and our sense of acquaintance are causally and psychologically related, as the first systematically causes the second. In that case, the first would indeed explain the second. I will now argue that this is not the case: certainty does not systematically cause a sense of acquaintance.

Why do I think certainty does not systematically cause a sense of acquaintance? One first reason to think so comes from the case of a priori truths - logical truths, definitional truths, mathematical truths (Kammerer, 2019c, p. 125). Take statements such as " $1+1=2 "$ ", "all bachelors are unmarried", "If $\mathrm{P}$ and $(\mathrm{P} \rightarrow \mathrm{Q})$, then Q". Arguably, we are fully certain of the truth of these statements, and yet it is not clear that we have a sense of acquaintance with the entities involved here. Consider numbers, bachelors, the meaning of the word "bachelor", or the material conditional: none of these entities seem presented to us as experiences are - in the same concrete, direct and revelatory way. Therefore, some a priori propositions are believed with certainty without us having a corresponding sense of acquaintance. This suggests that certainty is not enough to generate a sense of acquaintance. ${ }^{16}$

\footnotetext{
${ }^{16}$ Certainty here means "full certainty"; but what I said could also apply to meta-certainty (as we arguably believe with certainty that we are certain of such a priori truths). As for near-certainty, it encounters even more serious problems, given that we are nearly certain of a great deal of very mundane truths - as noted earlier.
} 
One could object to this counterexample, for two reasons. First, one might point out that a priori propositions are justified in very peculiar ways, which sets them apart from a posteriori propositions (such as propositions about phenomenal states); and maybe it is only certainty regarding a posteriori propositions which generates a sense of acquaintance. One could of course wonder why this is so (what is so peculiar about a posteriori certainty? ${ }^{17}$ ), but the fact that there exists an important difference of status between these propositions (a priori) and phenomenal propositions (a posteriori) weakens the counterexample. Second, one might also bite the bullet and claim that, in the case of a priori certainty, we do have a sense of acquaintance with the corresponding entities (numbers, properties and logical relations). After all, Russell himself, who first introduced the concept of knowledge by acquaintance, claimed that we are acquainted, not only with what we experiences (sense data), but also with universals (Russell, 1912) - with numbers, properties and relations. Whether we really have a sense of acquaintance with such entities might of course be discussed (most people do not think that properties - say, being a prime number or being a grandmother - are presented to them in the same concrete way as their experiences!), but the thesis is defensible. For these two reasons, even if the case of a priori truths should make us suspicious of the idea that certainty systematically causes a sense of acquaintance, we should try to argue against this thesis without relying on this one counterexample.

Now, let us turn to a thought experiment designed to show that certainty does not systematically cause a sense of acquaintance. This only involves a posteriori propositions.

Martian Faith: You wake up one morning with the definitive and overwhelming conviction that there is intelligent life on Mars. You are (psychologically) 100\% certain of this; and you are also (psychologically) 100\% certain that you indeed have this kind of certainty. You would bet your life a thousand times on there being intelligent Martians, without hesitation. Now, when you ask yourself "how do I know it?", you admit you did not go to Mars - nor were you contacted by Martians. In fact, you do not have any reason to believe that there is intelligent life on Mars - not in the ordinary sense of reason, that is, other than the mere fact that you take

\footnotetext{
${ }^{17}$ See my footnote 7 for elements in Clark et al.'s account, which might help here.
} 
this to be true. It just happened to you: you woke up one morning believing that there are intelligent aliens on Mars (the true cause of your belief might be, say, a very localized brain stroke that occurred during the night, but you need not know that). You might then come up with hypotheses about how your "knowledge" was obtained. Maybe you received some sort of divine revelation? Maybe you secretly have some super-human faculty of intuition? Maybe you saw the Martians, and were then treated with some sort of Men In Black memory-erasure technology ("neuralyzer"), which did not work properly, as it suppressed all particular memories of your encounter, but left you with this one single piece of knowledge? Maybe you are just incredibly lucky, and formed an irrational belief (perhaps because of some localized brain stroke!) that simply happened to be true? At any rate, you also easily recognize that these are mere hypotheses, and that they might very well turn out to be false. The only thing you are unshakably certain of is the fact that there is intelligent life on Mars.

In Martian Faith, someone develops full certainty (as well as meta-certainty, say - certainty that one is certain) towards a given a posteriori proposition (that there is intelligent life on Mars) but fails to develop any robust sense of acquaintance regarding the corresponding entities. The story tries to make it palpable that you can have unshakable faith in something (the existence of the Martians) without having a robust and persisting impression that you have some sort of special epistemic access to that thing (what happens on Mars).

Martian Faith describes what could follow from developing full certainty regarding a certain proposition; it shows that a sense of acquaintance does not have to ensue. Is this aspect of Martian Faith psychologically plausible? I hope the story gives the reader a sense that it is; but if it is, then that means that there is no systematic psychological causal relation from full certainty and meta-certainty to a sense of acquaintance (obviously, near-certainty would not help here). This suggests that there is no systematic psychological link between certainty (of any kind) and a sense of acquaintance. This gives a reason to deny that designed certainty views explain our sense of acquaintance. 
Proponents of designed certainty views might push back on this, in at least two ways. First, they could argue that, even though there might be no systematic causal relation between certainty and a sense of acquaintance, there could nevertheless be a causal relation in some cases. After all, the protagonist of Martian Faith comes up with hypotheses to account for their sudden knowledge of extraterrestrial facts. Could we not imagine that, in some cases, someone in that situation ends up believing strongly in some of these hypotheses - maybe, precisely, the ones that imply that facts about Mars are immediately presented and revealed to the protagonist? This would come close to believing in some form of acquaintance with Martian facts. If something similar happens in the case of phenomenal experiences, then designed certainty views could contribute to explain our sense of acquaintance with experiences.

This seems like a plausible story. The only problem is that it would make our sense of acquaintance the result of some kind of reasoning - by which we come to form and embrace a hypothesis. This, in turn, should make our sense of acquaintance the result of a cognitively penetrable process. One should be able, with enough attention and effort, to distinguish between what one cannot control (one's certainty that one is conscious) and the hypotheses one makes regarding the origin and justification of such certainty. This would make designed certainty views close to older views that see our sense of acquaintance as the result of some (possibly mistaken) reasoning process, which we should be able to control and inhibit if necessary. I presupposed earlier the falsity of such views, and I think that designed certainty views would lose a great part of their appeal if they concluded that our sense of acquaintance was a mere hypothesis - that we are free to endorse or to reject - rather than something unavoidable.

Second, proponents of designed certainty views might maintain that there is in fact a systematic psychological connection between certainty and a sense of acquaintance, and that Martian Faith is not psychologically plausible. I find Martian Faith extremely plausible, but it is, after all, a mere thought experiment: it might be that I am simply wrong when I imagine what would happen if I became suddenly fully certain of something (armchair psychology has - justifiably - a bad reputation). However, some empirical facts can help me strengthen my case here. Indeed, some actual situations can be read as (imperfect) real-life equivalents of Martian Faith: monothematic delusions. In monothematic delusions (Bortolotti, 2018), subjects hold, with great conviction, and in a way resistant to counter-argumentation, beliefs which are usually 
judged "strange", if not plainly absurd. The delusions are monothematic when they concern only one theme (subjects do not tend to hold strange beliefs about other topics). Classic examples of such delusions include the Capgras delusion (the delusional belief that an impostor has replaced a relative or a spouse) and the Cotard delusion (subjects believe of themselves that they are disembodied, dead, or nonexistent).

Many delusional subjects seem able to recognize the strangeness of their beliefs. Yet, they do not systematically tend to form supplementary beliefs about their hypothetical access to supplementary information, which would lend support to their delusions. In other words: in many cases, delusional subjects believe with unshakable certainty that a strange fact obtains and they recognize the strangeness or their belief, without developing a sense that they have a special and unique access to such a strange fact (which would ground their certainty). Here, for example, is what a Capgras subject (S) said, when asked about their beliefs:

E : Isn't that [two families] unusual ? S : It was unbelievable. E : How do you account for it ? S : I don't know. I have tried to understand it myself and it was virtually impossible. E : What if I told you I don't believe it ? S : That's perfectly understandable. In fact, when I tell the story, I feel that I'm concocting a story... it's not quite right, something is wrong. E : If someone told you the story what would you think ? S : I would find it extremely hard to believe. I should be defending myself. (Alexander et al., 1979, p. 335).

Here is a Cotard subject (LU), who believes that she is dead, but confesses that she has no idea of how she died:

When asked how she thought she had died, LU replied 'I don't know how. Now I know that I had a flu and came here on 19th November. Maybe I died of the flu." (McKay \& Cipolotti, 2007, p. 353) 
Even when they give justifications for their beliefs, delusional subjects often seem to provide justifications which are very different from a hypothetical appeal to "acquaintance". These justifications might consist in appeals to mundane and ordinary facts (which would ordinarily be judged insufficient to justify the kind of extraordinary beliefs held by the subjects). For example, a Capgras subject who believed that her daughter had been replaced by an impostor gave two justifications for her belief. (A) The person she believes to be an impostor (in fact, her daughter) had worn too much makeup compared to her real daughter, and (B) there was some incoherence in the information she received regarding the distance of the workplace of the person who claimed to be her daughter (Luca et al., 2013, p. 1096).

None of this is proof that even some delusional subjects lack a sense of acquaintance with the fact they are delusional about, but it strongly suggests so. Indeed, if all delusional subjects (or even simply most of them) developed a sense of acquaintance regarding the strange fact they are delusional about, we should expect this sense of acquaintance to show up in their answers when they are asked to defend their beliefs. However, this does not seem to be the case.

Therefore, the case of monothematic delusions supports the idea that believing with certainty that some facts obtain does not reliably cause a sense of acquaintance with the same facts. Of course, objections could be opposed to this argument from monothematic delusions. It might be that delusional subjects do in fact have a sense of acquaintance with the facts they are delusional about, but that it did not show up in their answers because they were not appropriately probed. It might also be that their delusions are not proper beliefs (Berrios, 1991; Currie, 2000), or maybe that, even though they are beliefs, they are not really held with certainty. Finally, it might be that delusional subjects hold their delusional beliefs with certainty, and that they lack a sense of acquaintance, but only because the mechanism normally responsible for the causal link between certainty and the sense of acquaintance breaks down in their case. After all, they are pathological subjects, and we should not expect their cognitive functioning to mirror exactly the functioning of "normal" subjects.

Nevertheless, even if all these answers are available in principle, they all have in turn a certain cost. So, I think it is fair to say that, taken together with the cases of a priori truths and the plausibility of Martian Faith, the case of monothematic delusion puts some very serious 
This is draft. Please do not cite without authorization

pressure on the thesis that psychological certainty systematically causes a sense of acquaintance.

Therefore, certainty about experiences does not constitute our sense of acquaintance with experiences, and it does not plausibly cause it systematically either. Hence, certainty about experiences does not explain our sense of acquaintance with experiences.

\section{Conclusion}

Solving the meta-problem of consciousness requires explaining our sense of acquaintance with experiences. While designed certainty views might have appeared as promising candidate theories to explain such a sense of acquaintance, they must be rejected. It is doubtful that we really hold phenomenal beliefs with certainty (at least in a sense of certainty that would be distinctive enough of phenomenal beliefs). Moreover, even if we did hold phenomenal beliefs with certainty, this would not account for our sense of acquaintance, given that certainty would not constitute nor systematically cause such a sense of acquaintance. We should look away from certainty in our search for an explanation of our sense of acquaintance. My own view, developed and defended elsewhere (Kammerer, 2019c, 2019b), is that our sense of acquaintance derives from the content of our introspective representations: we represent phenomenal consciousness, so to speak, as an entity with which we are in a certain kind of epistemological relation - a relation that philosophical elaboration presents under the guise of "acquaintance". But here is not the place to elaborate my positive account of our sense of acquaintance.

\section{References}


This is draft. Please do not cite without authorization

Alexander, M. P., Stuss, D. T., \& Benson, D. F. (1979). Capgras syndrome. Neurology, 29(3), 334. https://doi.org/10.1212/WNL.29.3.334

Armstrong, D. M. (1968). The headless woman illusion and the defence of materialism. Analysis, 29(2), 48-49. https://doi.org/10.1093/analys/29.2.48

Balmer, A. (2020). Soft-Wired Illusionism Versus the Meta-Problem of Consciousness. Journal of Consciousness Studies, 27(5-6), 26-37.

Balog, K. (2020). Disillusioned. Journal of Consciousness Studies, 27(5-6), 38-53.

Balog, K. (2012). Acquaintance and the Mind-Body problem. In C. Hill \& S. Gozzano (Eds.), New Perspectives on Type Identity: The Mental and the Physical (p. 16-42). Cambridge University Press.

Berrios, G. E. (1991). Delusions as "Wrong Beliefs": A Conceptual History. British Journal of Psychiatry, 159(S14), 6-13. Cambridge Core. https://doi.org/10.1192/S0007125000296414

Blackmore, S. (2002). There Is No Stream of Consciousness. Journal of Consciousness Studies, 9(5-6), 17-28.

Block, N. (1995). On a confusion about a function of consciousness. Brain and Behavioral Sciences, 18, 227-247.

Bortolotti, L. (2018). Delusion. In E. Zalta (Ed.), Stanford Encyclopedia of Philosophy (Spring 2018 Edition). https://plato.stanford.edu/archives/spr2018/entries/delusion/ 
This is draft. Please do not cite without authorization

Byrne, A. (2009). Experience and Content. Philosophical Quarterly, 59(236), 429-451.

Chalmers, D. (1995). Facing up to the problem of consciousness. Journal of Consciousness Studies, 2(3), 200-219.

Chalmers, D. (2018). The Meta-Problem of Consciousness. Journal of Consciousness Studies, 25(9-10), 6-61.

Chalmers, D. (2020). How Can We Solve the Meta-Problem of Consciousness. Journal of Consciousness Studies, 27(5-6), 201-226.

Clark, A. (2019). Consciousness as Generative Entanglement. Journal of Philosophy, 116(12), 645-662. https://doi.org/10.5840/jphil20191161241

Clark, A., Friston, K., \& Wilkinson, S. (2019). Bayesing Qualia: Consciousness as Inference, not Raw Datum. Journal of Consciousness Studies, 26(9-10), 19-33.

Coleman, S. (2018). Natural Acquaintance. In J. Knowles \& T. Raleigh (Eds.), New Essays on Acquaintance. Oxford University Press.

Currie, G. (2000). Imagination, Delusion and Hallucinations. Mind \& Language, 15(1), 168-183. https://doi.org/10.1111/1468-0017.00128

Dennett, D. (2017). From Bacteria to Bach and Back. Norton \& Company.

Dretske, F. (1995). Naturalizing the Mind. MIT Press. 
This is draft. Please do not cite without authorization

Frankish, K. (2016). Illusionism as a Theory of Consciousness. Journal of Consciousness Studies, 23(11-12), 11-39.

Harman, G. (1990). The intrinsic quality of experience. In J. Tomberlin (Ed.), Philosophical Perspectives, 4: Action Theory and Philosophy of Mind. Ridgeview.

Hill, C. (1991). Sensations: A Defense of Type Materialism. Cambridge University Press.

Irvine, E. (2019). Explaining variation within the meta-problem. Journal of Consciousness Studies, 26(9-10), 115-123.

Kammerer, F. (2018). Can you believe it? Illusionism and the illusion meta-problem. Philosophical Psychology, 31(1), 44-67.

Kammerer, F. (2019a). How rich is the illusion of consciousness? Erkenntnis. https://doi.org/doi:10.1007/s10670-019-00204-4

Kammerer, F. (2019b). The illusion of conscious experience. Synthese. https://doi.org/10.1007/s11229-018-02071-y

Kammerer, F. (2019c). The Meta-Problem of Consciousness and the Evidential Approach. Journal of Consciousness Studies, 26(9-10), 124-135.

Kriegel, U. (2009). Subjective Consciousness : A Self-Representational Theory. Oxford University Press.

Lau, H., \& Michel, M. (2019). A Socio-Historical Take on the Meta-Problem of Consciousness. Journal of Consciousness Studies, 26(9-10), 136-147. 
This is draft. Please do not cite without authorization

Lewis, D. (1995). Should a Materialist Believe in Qualia? Australasian Journal of Philosophy, 73(1), 140-44. https://doi.org/10.1080/00048409512346451

Luca, M., Bordone, A., Luca, A., Patti, A., Sortino, G., \& Calandra, C. (2013). Clinical features and imaging findings in a case of Capgras syndrome. Neuropsychiatric Disease and Treatment, 9, 1095-1099. PubMed. https://doi.org/10.2147/NDT.S47293

McCauley, R. N., \& Henrich, J. (2006). Susceptibility to the Müller-Lyer Illusion, TheoryNeutral Observation, and the Diachronic Penetrability of the Visual Input System. Philosophical Psychology, 19(1), 79-101. https://doi.org/10.1080/09515080500462347

McKay, R., \& Cipolotti, L. (2007). Attributional style in a case of Cotard delusion. Consciousness and Cognition, 16(2), 349-359. https://doi.org/10.1016/j.concog.2006.06.001

Pereboom, D. (2009). Consciousness and Introspective Inaccuracy. In L. Jorgensen \& S. Newlands (Eds.), Appearance, Reality, and the Good: Themes from the Philosophy of Robert M. Adams (p. 156-187). Oxford University Press.

Pereboom, D. (2011). Consciousness and the Prospects of Physicalism. Oxford University Press.

Pereboom, D. (2019). Russellian Monism, Introspective Inaccuracy, and the Illusion MetaProblem of Consciousness. Journal of Consciousness Studies, 26(9-10), 182-193.

Reed, B. (2011). Certainty. In E. N. Zalta (Ed.), The Stanford Encyclopedia of Philosophy (Winter 2011). https://plato.stanford.edu/archives/win2011/entries/certainty/ 
This is draft. Please do not cite without authorization

Russell, B. (1912). The Problems of Philosophy. Oxford University Press.

Schwarz, W. (2018). Imaginary Foundations. Ergo, 5(29).

Schwarz, W. (2019). From Sensor Variables to Phenomenal Facts. Journal of Consciousness Studies, 26(9-10), 217-227.

Smart, J. J. C. (1959). Sensations and Brain Processes. Philosophical Review, 68, 141-156.

Sytsma, J., \& Machery, E. (2010). Two conceptions of subjective experience. Philosophical Studies, 151(2), 299-327.

Sytsma, J., \& Ozdemir, E. (2019). No Problem: Evidence that the Concept of Phenomenal Consciousness is Not Widespread. Journal of Consciousness Studies, 26(9-10), 241-256.

Tye, M. (2002). Representationalism and the Transparency of Experience. Noûs, 36(1), $137-151$

Wierzbicka, A. (2010). Experience, evidence, and sense: The hidden cultural legacy of English. Oxford University Press.

Wierzbicka, A. (2019). "From 'consciousness' to 'I think, I feel, I know'”. Journal of Consciousness Studies, 26(9-10), 257-269.

Williford, K. (2020). Headlessness without Illusions: Phenomenological Undecidability and Materialism. Journal of Consciousness Studies, 27(5-6), 190-200. 
